\title{
Adenomyoepithelioma of the breast with prominent cystic changes: a case report
}

\author{
Feng Chen* ${ }^{*}$, Hengping Wu, Yujian Liu, Minli Lv and Jianquan Zhong
}

\begin{abstract}
Background: Adenomyoepithelioma (AME) of the breast is a rare subtype of breast tumor. Most of AMEs reported are solid, however, cystic or prominent cystic changes are extremely rare.

Case presentation: A 51-year-old woman presented a lump in the upper outer quadrant of right breast, and it was accompanied by continuous breast pain and bilateral axillary itching for more than 2 months. There were no other symptoms found. Preoperative mammography and ultrasound examination were performed. Mammography showed a noncalcified lobulated mass, and it was considered to be a benign cyst with septum on ultrasound, but ductal carcinoma of breast, adenoid cystic carcinoma could not be excluded. At first, AME was not considered preoperatively, because the imaging features of this rare tumor may vary widely, which may result in an incorrect diagnosis. But eventually, AME was diagnosed by postoperative pathology and immunohistochemistry.

Conclusion: We herein present a rare case of breast AME with prominent cystic changes. AME has no-specific imaging features, but the benign or malignant nature of the lesion might be suspected on imaging.
\end{abstract}

Keywords: Adenomyoepithelioma, Breast, Cystic

\section{Background}

Adenomyoepithelioma (AME) of the breast was first described by Hamperl in 1970 [1]. According to the World Health Organization classification of breast tumors in 2012, AME was classified as epithelial-myoepithelial lesions [2]. AME is generally a benign breast tumor displaying proliferation of epithelial and myoepithelial cells, mainly myoepithelial hyperplasia. Tavasoli [3] subdivided AMEs into three variants, arranged in spindle cell type, tubules, and lobules. The diagnosis of AME was established by histopathology and immunohistochemistry. Most of AMEs showed solid mass rather than cystic mass [4], cystic or prominent cystic changes is extremely rare, in spite of a few may contain small cystic areas [5].

*Correspondence: cf1063443105@163.com

Department of Radiology, Zigong First People's Hospital, Zigong 643000,

Sichuan, People's Republic of China

\section{Case presentation}

A 51-year-old woman presented a lump in the upper outer quadrant of right breast, and it was accompanied by continuous breast pain and bilateral axillary itching for more than 2 months. There were no other symptoms found. Previously she didn't undergo any breast cancer screening, and had no family history of breast cancer. Physical examination revealed an irregular mass by palpation where was $3.5 \mathrm{~cm}$ away from the nipple, about $11 \mathrm{o}$ 'clock in the right breast, with hard texture, clear boundary, mobility and mild tenderness. Doppler ultrasound (Fig. 1a, b) showed no echogenic and irregular mass in the right breast, with solid striped septum, and weak echogenic deposition in the dorsal side, and the mass was well circumscribed. There was no blood flow signal in the lesion. Mammography (Fig. 1c, d) showed a lobed mass with slightly higher density in the right breast, smooth edge, partially concealed boundary, and there was no calcification in the mass. It was classified as category $4 \mathrm{~A}$ by BI-RADS assessment. It was considered to be a benign 

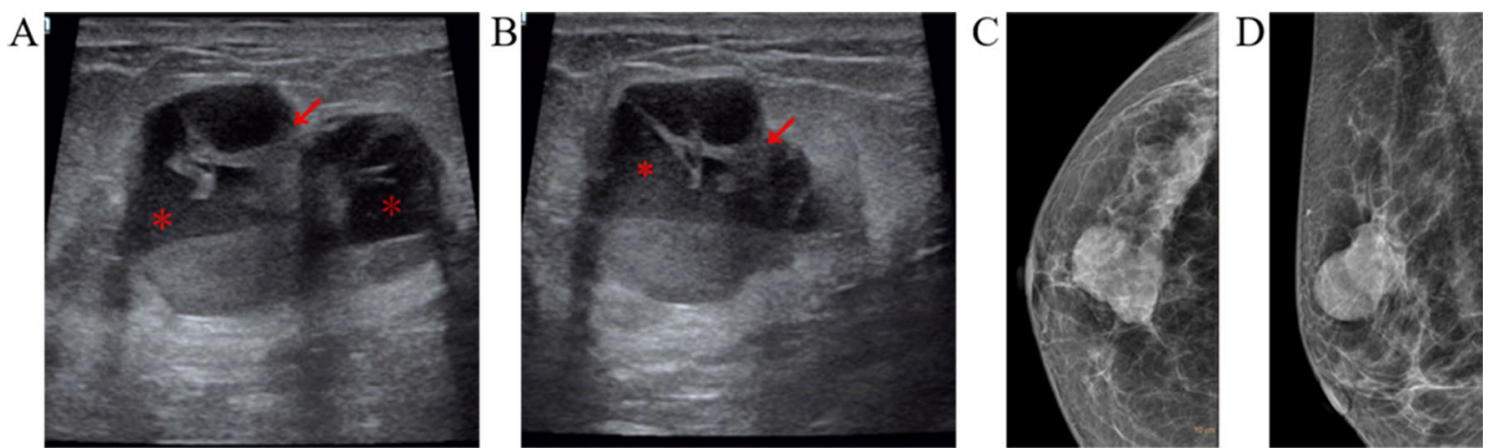

Fig. 1 a, b Ultrasonogram revealed no echogenic (red *) and well circumscribed mass with solid striped septum (red $\swarrow$ ), weak echogenic deposition in the dorsal side. $\mathbf{c}, \mathbf{d}$ On the CC and MLO mammograms showed lobulated mass without calcification

cyst with septum on ultrasound, but ductal carcinoma of breast, adenoid cystic carcinoma could not be excluded. We suggested the patient undergo MRI examination, but the patient refused. Since breast cancer could not be excluded, the patient was urged for a partial mastectomy. Postoperative general features: A $3.5 \mathrm{~cm} \times 3 \mathrm{~cm} \times 2.2 \mathrm{~cm}$ mass was observed at $11 \mathrm{o}$ 'clock of the right breast, $3.0 \mathrm{~cm}$ from the nipple, with an unclear boundary and enveloped, also a $2.8 \mathrm{~cm}$ maximum diameter cyst was observed on the section, and a $2.2 \mathrm{~cm} \times 1.8 \mathrm{~cm} \times 1.5 \mathrm{~cm}$ gray-white neoplasm was observed inside the cyst. Micrographs of histological specimens with HE staining (Fig. 2a) showed the mass was biphasic appearance. The outer myoepithelial cells were single or multilaye, the cytoplasm was clear and the nuclei was not atypia. The inner layer were glandular epithelial cells, arranged in an adenoid structure, with abundant cytoplasm and no nuclear atypia. And immunohistochemistry (Fig. 2b-d) showed that: CK 5/6 (+, myoepithelial), P63 (+), calponin $(+$, myoepithelial), CK $(+)$, CK7 $(+$, epithelial), L-CK (+, epithelial), SMA (-), H-caldesmon (-), so it was diagnosed as AME. Because of the pathology and immunohistochemistry showed the tumor was well differentiated, she did not receice any further treatment after the surgery.

\section{Discussion and conclusions}

Breast AMEs are rare neoplasms. They have been described in patients ranging in age from 22 to 93 years [6], although most of them were elderly women, male cases were also reported [7]. AMEs are generally benign neoplasms, although a small number of malignant lesions have been reported in the literature, either the epithelial or myoepithelial component may undergo malignant transformation [8]. Some papers have concluded that AMEs over $2 \mathrm{~cm}$ should be treated as malignant [9]. Most of AMEs were solid, prominent cystic features of this tumor was extremely rare, in spite of rare minute cysts were described in a few cases of AMEs. A review of the literature indicates that only one case of cystic AME has been reported [10]. In our case, the patient had a large lesion with persistent breast pain. Although the lesions had prominent cystic changes, the boundary of some lesions was unclear, and she did not receive any further treatment after the surgery. It is important for the surgeon to achieve a clear margin when removing the tumor, because local recurrence or even malignant transformation can happen. So the patient still needed to be followed up to observe if malignant transformation occur after local lesion resection. Up to now, the patient has been followed up for half a year without recurrence or discomfort, and re-examination of ultrasound showed no abnormality. The radiological findings of breast AME are nonspecific. On ultrasound, AME typically presents as a solid, hypoechoic, small, irregular, or oval mass, often accompanied by posterior acoustic enhancement. Peripheral vascular enlargement has some features, and the mass may have catheter dilation $[11,12]$. Mammography is usually characterized by a noncalcified ovoid or lobulated mass with smooth margins $[13,14]$. MRI can provide additional information on the morphological and haemodynamic characteristics. On MRI, benign AMEs manifest as homogeneous signal on different sequences with Type I or II enhancement curves, while malignant AMEs presented as irregular and coarse-edged masses with type III enhanced curve [12, 15]. In our case, ultrasonography showed a lobulated mass with prominent cystic changes in the right breast, which was significantly different from the stereotypical AME images. Mammography shows a noncalcified lobulated mass, which is not significantly different from the common AME imaging findings due to the poor performance of the cystic changes on mammography. The prominent 

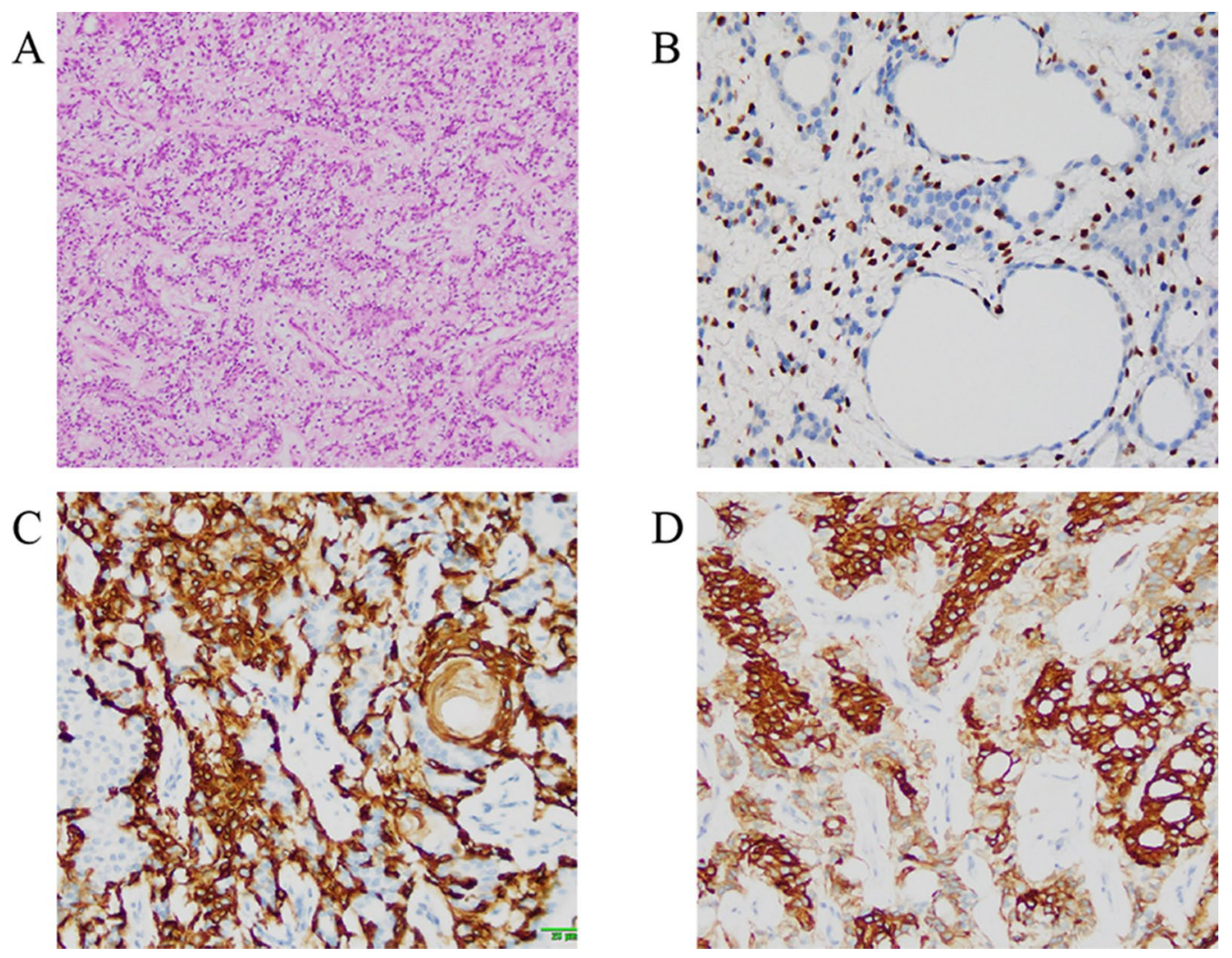

Fig. 2 a Photomicrograph of histologic specimen showed that the tumor was biphasic appearance, with inner layer of epithelial cells and outer layer of myoepithelial cells $(H E, \times 200)$. b Nuclear P63 staining in the myoepithelial component confirmed the differentiation of the myoepithelium (streptavidin-perosidase, $\times 200$ ). c CK5/6 highlights proliferating myoepithelial cells (streptavidin-perosidase, $\times 200$ ). $\mathbf{d}$ Epithelial cells were very strongly positive for CK7 (streptavidin-perosidase, $\times 200$ )

cystic features of the present tumor was easily misdiagnosed, so it's needed to be distinguished from ductal carcinoma of breast, adenoid cystic carcinoma, lobulated tumor, cyst of galactostasia, metaplasia carcinoma, etc. The imaging findings of these tumors did not differ significantly.

AME of breast is a rare and mostly benign tumor. AME has no-specific imaging features, but the benign or malignant nature of the lesion might be suspected on imaging.

\section{Acknowledgements}

Not applicable.

\section{Authors' contributions}

FC wrote the manuscript. HPW and MLL analyzed the data and revised the manuscript. YJL and JQZ was responsible for acquisiton, analysis and interpretation of the image. All authors read and approved the final manuscript.

\section{Funding}

Funding information is not applicable.

\section{Availability of data and materials}

Data sharing is not applicable to this article as no datasets were generated or analysed during the current study.

\section{Declarations}

Ethics approval and consent to participate Not applicable.

\section{Consent for publish}

The patient signed informed consent for the publication of this case report and any associated images. A copy of the consent form is available for review by the Editor of this journal.

\section{Competing interests}

The authors declare that they have no competing interests.

Received: 7 January 2021 Accepted: 23 July 2021

Published online: 04 August 2021

\section{References}

1. Hamperl H. The myothelia (myoepithelial cells). Normal state; regressive changes; hyperplasia; tumors. Curr Top Pathol. 1970;53:161-220.

2. Lakhani SR, Schnitt SJ, Tan PH, Vijver MJ. WHO Classification of Tumors of the Breast. World Health Organization Classification of Tumours. 2012.

3. Tavassoli FA. Myoepithelial lesions of the breast: myoepitheliosis, adenomyoepithelioma, and myoepithelial carcinoma. Am J Surg Pathol. 1991;15:554-68.

4. Rosen PP. Adenomyoepithelioma of the breast. Hum Pathol. 1987;18:1232-7. 
5. Kim MJ, Kim CS, Ju MJ, Park YS. Malignant adenomyoepithelioma of the breast: a rare case report. Int J Surg Case Rep. 2019;59:111-4.

6. Antonelli MS, Mallel G, Pecoraro A, Vitale V, Maggi S, Lombardi A, Stanzani $G$, Amanti C. Adenomyoepithelioma of the breast: case report and literature review. G Chir. 2018;39:255-7.

7. Gafton B, Scripcariu V, Prutianu I, Alexa-Stratulat T, Terinte C, Nicolau A, Moisiuc D, Radu I. Challenges in management of male breast adenomioepithelioma with malignant behavior: case report. Medicine (Baltimore). 2019:98:e17587.

8. Kakkar A, Jangra K, Kumar N, Sharma MC, Mathur SR, Deo SV. Epithelialmyoepithelial carcinoma of the breast: a rare type of malignant adenomyoepithelioma. Breast J. 2019;25:1273-5.

9. Korolczuk A, Amarowicz M, Bąk K, Korobowicz E, Koncewicz T. Adenomyoepithelioma of the breast with late pulmonary metastases_case report and review of the literature. J Cardiothorac Surg. 2016;11:121.

10. Papaevangelou A, Pougouras I, Liapi G, Pierrakakis S, Tibishrani M, Setakis N. Cystic adenomyoepithelioma of the breast. Breast. 2004;13:356-8.

11. Lee JH, Kim SH, Kang BJ, Lee AW, Song BJ. Ultrasonographic features of benign adenomyoepithelioma of the breast. Korean J Radiol. 2010;11:522-7.
12. Park YM, Park JS, Jung HS, Yoon HK, Yang WT. Imaging features of benign adenomyoepithelioma of the breast. J Clin Ultrasound. 2013;41:218-23.

13. Adejolu M, Wu Y, Santiago L, Yang WT. Adenomyoepithelial tumors of the breast: imaging findings with histopathologic correlation. AJR Am J Roentgenol. 2011;197:184-90.

14. Moritz AW, Wiedenhoefer JF, Profit AP, Jagirdar J. Breast adenomyoepithelioma and adenomyoepithelioma with carcinoma (malignant adenomyoepithelioma) with associated breast malignancies: a case series emphasizing histologic, radiologic, and clinical correlation. Breast. 2016:29:132-9

15. Zhang L, Qin G, He Z, Chen W, Yang L. The mammography and MRI manifestations of adenomyoepithelioma of the breast. Clin Radiol. 2016;71:235-43.

\section{Publisher's Note}

Springer Nature remains neutral with regard to jurisdictional claims in published maps and institutional affiliations.
Ready to submit your research? Choose BMC and benefit from:

- fast, convenient online submission

- thorough peer review by experienced researchers in your field

- rapid publication on acceptance

- support for research data, including large and complex data types

- gold Open Access which fosters wider collaboration and increased citations

- maximum visibility for your research: over $100 \mathrm{M}$ website views per year

At BMC, research is always in progress.

Learn more biomedcentral.com/submissions 